\title{
Readmissions of patients with diabetes mellitus and foot ulcers after infra-popliteal bypass surgery - attacking the problem by an integrated case management model
}

\author{
Gerhard Rümenapf $^{1}$, Sandra Geiger ${ }^{2}$, Brigitte Schneider ${ }^{1}$, Klaus Amendt ${ }^{1}$, Norbert Wilhelm ${ }^{3}$, \\ Stephan Morbach ${ }^{4}$, and Norbert Nagel $^{5}$ \\ ${ }^{1}$ Department of Vascular Surgery, Gefäßzentrum Oberrhein Speyer-Mannheim, \\ Diakonissen-Stiftungs-Krankenhaus Speyer, Germany \\ ${ }^{2}$ Case Management, Diakonissen-Stiftungs-Krankenhaus Speyer, Germany \\ ${ }^{3}$ Konzeptmanagement, B. Braun Melsungen AG, Melsungen, Germany \\ ${ }^{4}$ Department of Diabetes and Angiology, Marienkrankenhaus Soest, Germany \\ ${ }^{5}$ Medical Scientific Affairs, B. Braun Melsungen AG, Melsungen, Germany
}

\section{Summary}

Background: Patients with neuroischemic diabetic foot syndrome (DFS) may need arterial revascularization, minor amputations, débridements as well as meticulous wound care. Unfortunately, postoperative outpatient care is frequently inadequate. This is especially true for Germany, where the in- and outpatient sectors are funded and managed separately, with poor communication between the two. Thus, many patients may be readmitted to the hospital following successful treatment and discharge. In an attempt to overcome these problems, we looked at whether an integrated case management (CM) system for outpatient care according to in-hospital standards might improve patients care and avoid readmissions. In addition we analyzed the length of hospital stay (LOS) as well as hospital costs.

Patients and methods: In this retrospective cohort study patients with DFS, bypass surgery and foot surgery after implementation of the CM (study group; $\mathrm{n}=376$ ) were compared with a matched historic control group (HCG; $\mathrm{n}=190)$ including the flat rate revenues (G-DRG K01B). Following a standardized assessment, integrated trans-sectoral CM care was offered to 116 patients (CMP).

Results: The proportion of patients who were readmitted to hospital was reduced in CMP compared to HCG (8.8 vs. $16.4 \%$; $<0.01$ ), with consequent reduction of case consolidations $(9.7 \%$ versus $17.8 \%, \mathrm{p}<0.001)$. Although initially, the mean LOS was higher in the CMP patients, the reduction in readmissions meant that this integrated CM program improved the hospital's economic situation.

Conclusions: A hospital-based integrated CM system significantly reduces the hospital readmissions in patients with neuroischemic DFS following bypass surgery, with lower hospital costs.

Key words: Integrated case management, case merge, case consolidation, diabetic foot syndrome, hospital readmission, revascularization

\section{Zusammenfassung}

Stationäre Wiedereinweisung von Patienten mit Diabetes mellitus und Fußulzera nach gefäßchirurgischer Revaskularisation. Einfluss eines sektoren-übergreifenden Fallmanagements Hintergrund: Patienten mit neuroischämischem diabetischem Fußsyndrom (DFS) brauchen arterielle Revaskularisationen, Minoramputationen, Débridements und eine sorgfältige Wundversorgung. In vielen Ländern ist die ambulante Weiterversorgung dieser Patienten häufig unzureichend. Das trifft insbesondere für Deutschland zu, wo die ambulanten und stationären Sektoren finanziell, organisatorisch und hinsichtlich der intersektoralen Kommunikation strikt voneinander getrennt sind. Dadurch kommt es trotz erfolgreicher klinischer Behandlung zu vielen stationären Wiedereinweisungen. Wir haben untersucht, ob ein integriertes, sektorenübergreifendes Case Management (CM) für die ambulante Betreuung nach klinischen Standards die Zahl der stationären Wiedereinweisungen und Fallzusammmenführungen sowie die Kosten für das Krankenhaus senkt.

Patienten und Methoden: DFS-Patienten mit Bypassoperationen, Minoramputationen und Débridements an den Füssen nach Einführung des CM (Studiengruppe; n 376) wurden mit einer historischen Kontrollgruppe (HCG; $\mathrm{n}=190)$ verglichen. Nach einem standardisierten Assessment wurden 116 der 376 Patienten vom CM langfristig betreut (Case Management Patienten, CMP).

Ergebnisse: Die stationäre Wiederaufnahmerate der CMP war gegenüber HCG erniedrigt ( 8.8 vs. $16.4 \%$; $\mathrm{p}=0.001$ ), ebenso die Zahl der Fallzusammenführungen $(9.7 \%$ vs. $17.9 \%$; $\mathrm{p}=0.001$ ). Der stationäre Aufenthalt war bei den CMP initial signifikant länger als in HCG. Die ökonomische Situation der Klinik wurde trotzdem verbessert.

Schlussfolgerungen: Ein vom Krankenhaus aus organisiertes, klinische Qualitätskriterien zugrunde legendes, sektorenübergreifendes Fallmanagement senkt Wiederaufnahmen und Fallzusammenführungen von neuroischämischen DFS-Patienten nach arterieller Revaskularisation signifikant. Die Kosten für das Krankenhaus sinken. 


\section{Introduction}

The neuroischemic diabetic foot syndrome (DFS) causes chronic foot ulcers and accounts for some 20.000 major amputations per year in Germany $[4,11,16,22,34]$. Many of these may be prevented by early referral to a multidisciplinary service, aggressive treatment of infection, as well as by arterial revascularization, e.g. infrapopliteal bypasses [1, 13, 24, 26, 31], in combination with minor amputations or debridements [2, 27]. Specialized post-operative wound care supports the surgical success. Limb salvage is, however, often complicated by prolonged recovery, multiple reoperations and readmissions [10].

Economic pressure as well as increasing numbers of patients with DFS have resulted in a decrease of the hospital length of stay (LOS). Postoperative wound care is therefore often shifted to the outpatient sector. In Germany, the organization and financing of outpatient care is strictly separated from the hospital sector, being performed under economic as well as time pressure by private practice physicians. Communication between in- and out-patient health care professionals is lacking, and this combined with the often limited experience of outpatient therapists in postoperative wound care, leads to frequent readmissions and reduces the quality of life of the patients.

DFS treatment should be based on a multidisciplinary care concept $[2,34]$ including social, medical and surgical support as well as good interdisciplinary communication [32]. In Germany, disease management programs [36] as well as successful integrated care models $[12,30]$ were created for this purpose, resulting in low majoramputation rates and fewer hospital treatments [12]. However, effects on the rates of rehospitalisation of neuroischemic DFS patients, following initial in-patient treatment for arterial revascularization and surgical wound care were not reported.

The present study describes our efforts to improve the quality of patients care and to overcome the medical and psychological shortcomings of rehospitalization and prolonged LOS for the patients by an optimized discharge. We studied the effects of an integrated case management $(\mathrm{CM})$ system for patients with DFS, adjusting outpatient care to the clinical standards found within the hospital setting $[4,16,26]$, on readmission rates, LOS, and hospital costs.

\section{Patients and methods}

\section{Study design}

This retrospective cohort study with a historical control group comprised 566 post-operative patients (Tables IIII) with type 2 diabetes and neuroischemic DFS. All had foot wounds grade 3 or 4 according to Wagner [37], and stage $\mathrm{D}$ [ischemia and infection] according to the UT classification [3]. All patients underwent bypass surgery, along with minor amputations or débridements of their foot lesions, and all were allocated to the G-DRG K01B. The study groups were selected using the hospital documentation system (MedicoKIS; Siemens, Germany). All patients were discharged with care-intensive open foot wounds as well as healing surgical incisions. After implementation of the CM assessment, 376 patients with DFS from the years 2007 - 10 (study group) were compared with a historical control

Table I: Characteristics of study population - comorbidities

\begin{tabular}{|c|c|c|c|c|c|c|c|c|}
\hline \multirow[b]{2}{*}{ Age $($ mean \pm SD $)$} & \multicolumn{3}{|c|}{$\begin{array}{l}\text { Historic control group (HCG) } \\
\text { without CM assessement }\end{array}$} & \multicolumn{3}{|c|}{$\begin{array}{c}\text { Study group } \\
\text { with CM assessement }\end{array}$} & \multicolumn{2}{|c|}{$\begin{array}{l}\text { p-value } \\
\left(\chi^{2} \text {-test }\right)\end{array}$} \\
\hline & \multicolumn{3}{|c|}{$72,0 \pm 9,3$} & \multicolumn{3}{|c|}{$73,6 \pm 9,6$} & $0,1^{1)}$ & n.s. \\
\hline Gender & \multirow{2}{*}{\multicolumn{3}{|c|}{60,0}} & \multirow{2}{*}{\multicolumn{3}{|c|}{60,4}} & & \\
\hline Male $[\%]$ & & & & & & & 0,94 & n.s. \\
\hline Female $[\%]$ & \multicolumn{3}{|c|}{40,0} & \multicolumn{3}{|c|}{39,6} & & \\
\hline \multicolumn{9}{|l|}{ Risk factors and comorbidities ${ }^{2}$} \\
\hline Essential (primary) hypertension (I10.-) & 61,6 & {$[54,5$} & ; 68,3 ] & 55,4 & 48,6 & ; 62,2$]$ & 0,22 & n.s. \\
\hline Chronic renal failure (N18.-) & 39,5 & {$[32,7$} & ; 46,5 ] & 48,5 & 41,7 & ; 55,4$]$ & 0,07 & n.s. \\
\hline Heart failure (I50.-) & 36,8 & [ 30,2 & ; 43,9 ] & 38,6 & 32,1 & $; 45,5]$ & 0,72 & n.s. \\
\hline Hyperlipedemia (E78.-) & 26,3 & [ 20,4 & ; 32,9 ] & 26,7 & 21,0 & ; 33,1 ] & 0,93 & n.s. \\
\hline Hyperuricemia (E79.0) & 22,1 & {$[16,7$} & ; 28,4$]$ & 22,3 & 17,0 & ; 28,4 ] & 0,97 & n.s. \\
\hline Active smoker (F17.2) & 10,5 & {$[\quad 6,8$} & ; 15,5$]$ & 7,4 & 4,4 & ; 11,7 ] & 0,28 & n.s. \\
\hline
\end{tabular}




\section{Original communication}

Table II: Characteristics of study population - procedures

\begin{tabular}{|c|c|c|c|c|c|c|c|c|}
\hline & \multicolumn{3}{|c|}{$\begin{array}{l}\text { Historic control group } \\
\text { (HCG) } \\
\text { without CM assessement }\end{array}$} & \multicolumn{3}{|c|}{$\begin{array}{l}\text { Study group } \\
\text { with } \\
\text { CM assessement }\end{array}$} & \multicolumn{2}{|c|}{$\begin{array}{l}\text { p-value } \\
\left(\chi^{2} \text {-test }\right)\end{array}$} \\
\hline \multicolumn{9}{|l|}{ Surgical procedures ${ }^{1)}$} \\
\hline Bypass surgery $(5-393)$ & 97,9 & {$[95,1$} & ; 99,3 ] & 97,0 & {$[94,0$} & ; 98,8$]$ & 0,59 & n.s. ${ }^{2)}$ \\
\hline Vein harvesting $(5-386)$ & 75,3 & {$[68,8$} & ; 81,0$]$ & 73,8 & [ 67,4 & ; 79,5 ] & 0,73 & n.s. \\
\hline Wound debridement (5-893), total & 65,3 & {$[58,3$} & ; 71,8$]$ & 70,3 & {$[63,7$} & ; 76,3$]$ & 0,29 & n.s. \\
\hline Major amputation $(5-864)^{3)}$ & 13,2 & {$[8,9$} & ; 18,5$]$ & 8,9 & {$[5,6$} & ; 13,4$]$ & 0,18 & n.s. \\
\hline Minor amputation $(5-865)^{3)}$ & 57,4 & {$[50,3$} & ; 64,2 ] & 55,4 & {$[48,6$} & ; 62,2$]$ & 0,70 & n.s. \\
\hline Revision of arterial reconstruction $(5-394)$ & 30,5 & {$[24,3$} & ; 37,3 ] & 23,8 & {$[18,3$} & ; 30,0 ] & 0,13 & n.s. \\
\hline \multicolumn{9}{|l|}{ Non-surgical and therapeutic procedures } \\
\hline Blood transfusion $(8-800)$ & 36,3 & {$[29,7$} & ; 43,3 ] & 34,7 & {$[28,3$} & ; 41,4$]$ & 0,73 & n.s. \\
\hline Monitoring of respiration and circulation $(8-930)$ & 12,1 & {$[8,0$} & ; 17,3 ] & 13,9 & {$[9,6$} & ; 19,1$]$ & 0,61 & n.s. \\
\hline Special dressing techniques (VAC-therapy) $(8-190.1)$ & 8,4 & {$[5,1$} & ; 13,0$]$ & 11,4 & {$[7,6$} & $; 16,3]$ & 0,33 & n.s. \\
\hline $\begin{array}{l}\text { Complex treatment after colonisation or infection } \\
\text { with multiresistant pathogenes }(8-987)\end{array}$ & 11,1 & {$[\quad 7,2$} & ; 16,1$]$ & 10,9 & {$[7,2$} & ; 15,7 ] & 0,96 & n.s. \\
\hline \multicolumn{9}{|l|}{ Revascularization } \\
\hline A. femoralis $(5-393.5)$ & 71,6 & {$[64,9$} & ; 77,6 ] & 61,9 & {$[55,1$} & ; 68,4$]$ & 0,04 & s. \\
\hline$-5-393.53$ & 24,2 & {$[18,5$} & ; 30,7 ] & 25,2 & {$[19,6$} & ; 31,6 ] & 0,81 & n.s. \\
\hline$-5-393.54$ & 17,9 & {$[13,0$} & ; 23,8 ] & 12,4 & {$[8,4$} & $; 17,4]$ & 0,13 & n.s. \\
\hline$-5-393.55$ & 33,2 & {$[26,8$} & ; 40,1 ] & 22,8 & {$[17,4$} & ; 28,9 ] & 0,02 & s. \\
\hline A. poplitea $(5-393.6)$ & 26,8 & {$[20,9$} & ; 33,5 ] & 36,1 & {$[29,7$} & ; 42,9 ] & 0,05 & n.s. \\
\hline$-5-393.61$ & 16,8 & {$[12,0$} & ; 22,6 ] & 20,3 & {$[15,2$} & ; 26,2 ] & 0,38 & n.s. \\
\hline$-5-393.62$ & 10,0 & {$[6,3$} & ; 14,9$]$ & 16,8 & {$[12,2$} & ; 22,4 ] & 0,05 & n.s. \\
\hline Lower leg arteries $(5-393.7)$ & 2,1 & {$[\quad 0,7$} & ; 4,9 ] & 2,0 & {$[0,7$} & ; 4,6$]$ & 0,93 & n.s. \\
\hline Intraoperative PTA $(8-836.0 ; 5-380.7 / 8)$ & 13,7 & {$[9,4$} & ; 19,1$]$ & 22,3 & {$[17,0$} & ; 28,4 ] & 0,03 & s. \\
\hline \multicolumn{9}{|l|}{ Transplant material } \\
\hline Autogenous (5-930.00/01) & 73,7 & {$[67,1$} & ; 79,6 ] & 64,9 & {$[58,1$} & ; 71,2 ] & 0,06 & n.s. \\
\hline Alloplastic (5-930.4) & 40,5 & {$[33,7$} & ; 47,6 ] & 38,1 & {$[31,6$} & ; 44,9 ] & 0,63 & n.s. \\
\hline $\begin{array}{l}\text { High-maintenance wounds } \\
\text { (debridement and amputation) }\end{array}$ & 98,9 & {$[96,7$} & ; 99,8$]$ & 98,5 & {$[96,1$} & ; 99,6 ] & 0,70 & n.s. \\
\hline \multicolumn{9}{|l|}{ Wound débridement, detail } \\
\hline - On foot $(5-893.0 \mathrm{~g} / \mathrm{g})$ & 16,3 & {$[11,6$} & ; 22,1 ] & 11,9 & {$[8,0$} & ; 16,9$]$ & 0,21 & n.s. \\
\hline - On lower leg (5-893.0f/1f) & 43,2 & {$[36,3$} & ; 50,3 ] & 40,6 & {$[34,0$} & ; 47,5 ] & 0,61 & n.s. \\
\hline \multicolumn{9}{|l|}{ Amputations, detail } \\
\hline \multicolumn{9}{|l|}{ Major } \\
\hline - single amputation site & 10,5 & {$[\quad 6,8$} & ; 15,5$]$ & 6,4 & {$[\quad 3,7$} & ; 10,5$]$ & 0,14 & n.s. \\
\hline - 2 amputation sites & 2,6 & {$[1,0$} & ; $\quad 5,7]$ & 2,5 & {$[1,0$} & ; $\quad 5,3]$ & 0,92 & n.s. \\
\hline \multicolumn{9}{|l|}{ Minor } \\
\hline - single amputation site & 33,2 & {$[26,8$} & ; 40,1 ] & 35,6 & {$[29,3$} & ; 42,4$]$ & 0,60 & n.s. \\
\hline - 2 amputation sites & 14,2 & {$[\quad 9,8$} & ; 19,7 ] & 12,4 & {$[7,7$} & ; 17,4$]$ & 0,59 & n.s. \\
\hline - 3 amputation sites & 6,8 & {$\left[\begin{array}{l}3,9 \\
0\end{array}\right.$} & ; 11,1$]$ & 4,0 & {$[1,3$} & ; $\quad 7,3$ ] & 0,21 & n.s. \\
\hline - 4 and more amputations sites & 3,2 & {$[1,3$} & ; 6,4$]$ & 3,5 & {$[1,3$} & ; $\quad 6,7$ ] & 0,87 & n.s. \\
\hline
\end{tabular}


Table III: Characteristics of the study subgroup after CM Assessment

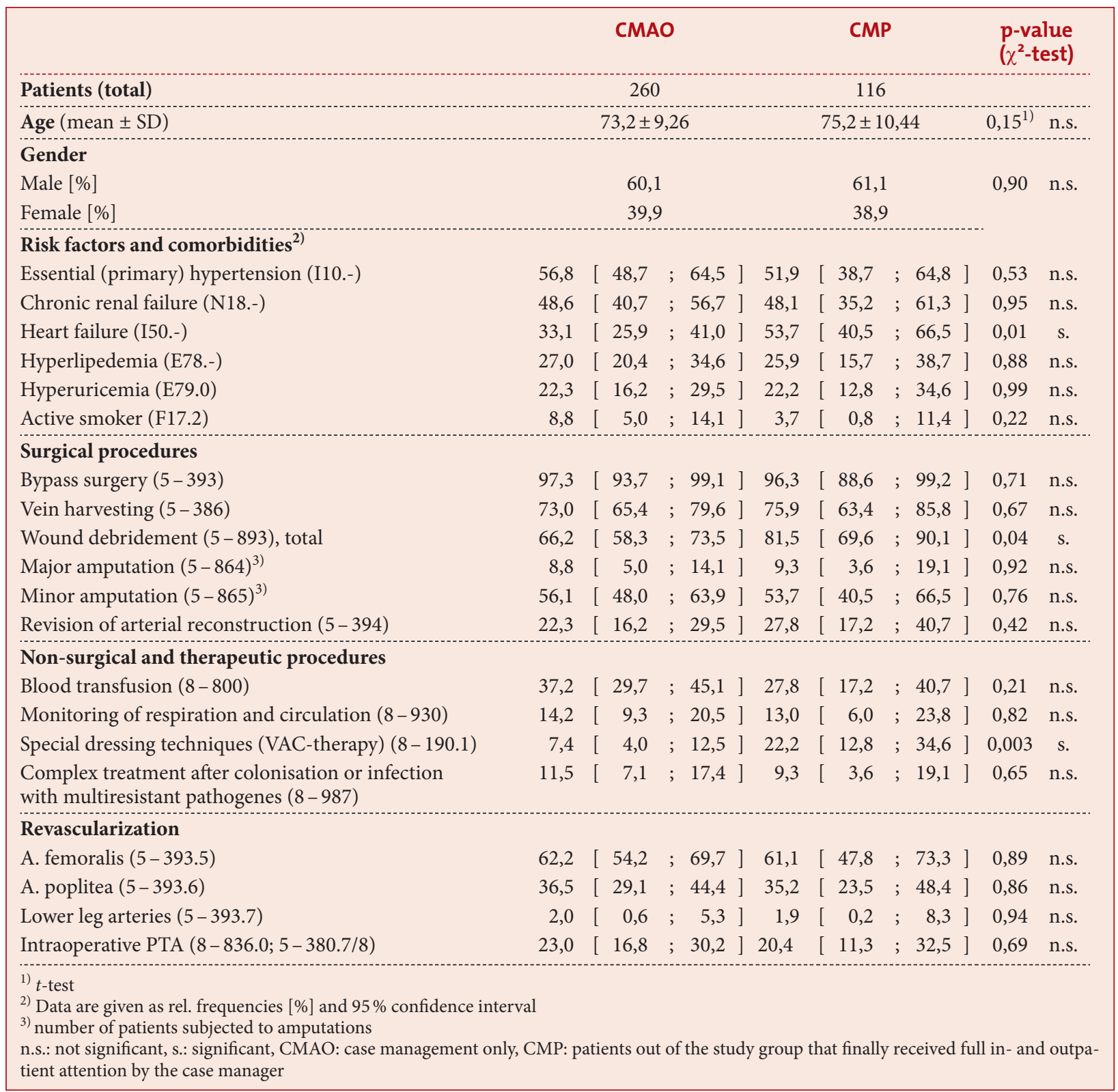

group from $2005-6$ (HCG; $\mathrm{n}=190)$ with no such an assessment. They were matched for age, sex, comorbidities and procedures (Tables I-III). Following the standardized CM assessment (see below), $116 \mathrm{CM}$ patients (CMP) out of the study group finally received full (in- and outpatient) attention by the CM, while 260 did not (CM assessment only, CMAO).

\section{Description of the case management}

Our "case management" system is a quality-controlled coordination of the peri- and postoperative in- and outpatient treatment of patients intended to achieve lasting therapeutic success by an improved discharge management (Figure 1, Table IV).

\section{Case manager}

Experienced nurses from our Department of Vascular Surgery were selected for extraordinary knowledge, social competence, communication skill, as well as personal authority. According to a curriculum developed by our hospital in cooperation with the B. Braun Melsungen concept management they were extensively 


\section{Original communication}

Table IV: Case finding by the Case Management Score

\begin{tabular}{|c|c|c|c|}
\hline \multicolumn{4}{|c|}{ Case Management (CM) Score for vascular surgery patients } \\
\hline Medical risk score & & Nursing risk score & Social risk score \\
\hline Risk factor & Pts. & Risk factor & Risk factor \\
\hline $\begin{array}{l}\text { Age } \\
\begin{array}{l}0=\leq 55 \text { years } \\
1=56 \text { to } 64 \text { years } \\
2=65 \text { to } 79 \text { years } \\
3=\geq 80 \text { years }\end{array}\end{array}$ & & $\begin{array}{l}\text { Cognitive abilities } \\
0=\text { orientated } \\
1=\text { in some areas of life (AoL) } \\
\text { sometimes disoriented } \\
2=\text { in some AoL always disoriented } \\
3=\text { in all AoL sometimes disoriented } \\
4=\text { in all AoL always disoriented } \\
4=\text { unconscious }\end{array}$ & $\begin{array}{l}\text { Living situations } \\
1=\text { nursing home } \\
1=\text { lives within his family } \\
2=\text { simple outpatient care } \\
\text { (e.g. insuline application) } \\
3=\text { living alone with assistance } \\
\text { of his family } \\
4=\text { living alone with assistance of } \\
\text { friends/ neighbors } \\
5=\text { living alone without } \\
\text { assistance } \\
6=\text { advanced outpatient care } \\
\text { (e.g. wound management) } \\
7=\text { advanced outpatient care } \\
\text { with (re)hospitalisation }\end{array}$ \\
\hline $\begin{array}{l}\text { Number of comorbidities } \\
0=\leq 5 \text { comorbidities } \\
1=6 \text { to } 8 \text { comorbidities } \\
2=\geq 9 \text { comorbidities }\end{array}$ & & $\begin{array}{l}\text { Sensoric deficits } \\
0=\text { NO } \\
1=\text { hearing OR visually impaired } \\
2=\text { hearing AND visually impaired }\end{array}$ & $\begin{array}{l}\text { Behavior pattern } \\
0=\text { without pathological findings } \\
1=\text { lacking in concentration; } \\
\text { disturbed } \\
2=\text { confused } \\
3=\text { self distructive }\end{array}$ \\
\hline $\begin{array}{l}\text { Wagner-Armstrong } \\
\text { Classification } \\
1=0 \mathrm{~A} / \mathrm{B} / \mathrm{C} ; 1 \mathrm{~A} \\
2=0 \mathrm{D} ; 1 \mathrm{~B} / \mathrm{C} ; 2 \mathrm{~A} \\
3=3-5 \mathrm{~A}: 2-5 \mathrm{~B} / \mathrm{C} ; 1-5 \mathrm{D}\end{array}$ & & $\begin{array}{l}\text { Mobility } \\
0=\text { mobile } \\
1=\text { mobile with devices } \\
2=\text { mobile with aide of other people } \\
3=\text { immobile, bedridden }\end{array}$ & \\
\hline $\begin{array}{l}\text { Diabetic polyneuropathy } \\
0=\text { NO } \\
1=\text { YES }\end{array}$ & & $\begin{array}{l}\text { Functional status } \\
0=\text { independent } \\
1=\text { limited }\end{array}$ & \\
\hline \multicolumn{4}{|l|}{$\begin{array}{l}\text { Rehospitalisation } \\
0=\text { no within } 3 \text { months } \\
1=\text { readmission within } 3 \\
\text { months }\end{array}$} \\
\hline \multicolumn{4}{|l|}{ Total CM Score $(A+B+C)$} \\
\hline Result: & $\begin{array}{l}\text { Total } \\
\text { Tota } \\
\text { CM }\end{array}$ & $\begin{array}{l}\text { CM score }<8 \text { : no case management; patient dis } \\
\text { CM score } 8 \text { to } 14 \text { : re-assessment } 3 \text { days post } \\
\text { core }>14 \text { : individual care by the case managen }\end{array}$ & $\begin{array}{l}\text { arged via general hospital social service } \\
\text { rative } \\
\text { at }\end{array}$ \\
\hline \multicolumn{4}{|c|}{ Post operative re-assessment } \\
\hline Risk factor & Pts & Risk factor & Risk factor \\
\hline $\begin{array}{l}\text { Complications } \\
0=\text { none } \\
1=\text { minor } \\
2=\text { major } \\
3=\text { critical } \\
\text { Sum }\end{array}$ & & $\begin{array}{l}\text { Wound healing } \\
0=\text { normal } \\
2=\text { impaired }\end{array}$ & $\begin{array}{l}\text { General state of health } \\
-1=\text { improved } \\
0=\text { no change } \\
2=\text { worsend }\end{array}$ \\
\hline Result of re-assessment: & \multicolumn{3}{|c|}{$\begin{array}{l}\text { Total CM score } \leq 14 \text { : no case management; patient discharged via general hospital social } \\
\text { service } \\
\text { Total CM score > 14: individual care by the case management }\end{array}$} \\
\hline
\end{tabular}




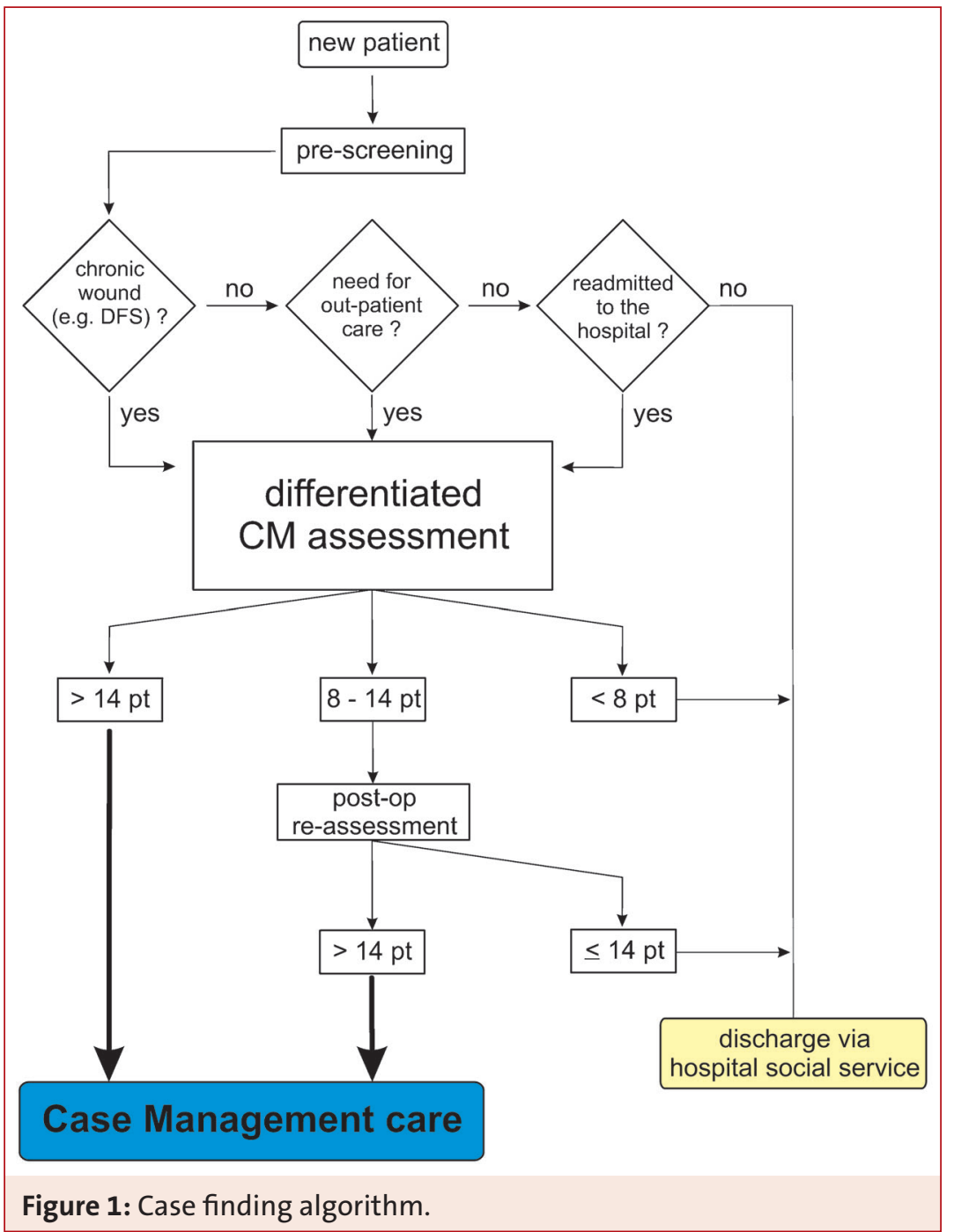

trained in modern wound management, public health sciences, health care management as well as practical case management.

Since 2007, all patients of our Department of Vascular Surgery were assessed for the need of CM support (Table IV, Figure 1).

\section{Screening and assessment}

Within 2 days of hospitalization patients were pre-screened during the ward round for chronic wounds, the need for outpatient care and/or care counseling, or whether they had already been readmitted to the hospital for the same principal diagnosis fol- lowing discharge (Figure 1). If one of these criteria was fulfilled, which was the case for all 376 patients in our study group, the patient underwent a differentiated assessment by the case manager.

In order to identify patients requiring intensive post-acute care, standard scores were determined by the nursing staff since 1999, such as the BRASS [22] and the Barthel index [20]. However, all 566 patients included in the present study met the criteria, i.e. these scores were not specific and sensitive enough to select those patients at highest risk of readmittance to the hospital. We therefore developed a case finding assessment using a new tripartite scoring system for our exceptionally problematic patients based on an analysis of the patient's medical, nursing and social situation (Figure 1, Table IV). In addition to those listed in Table 1, relevant comorbidities were e.g. coronary heart disease, a history of myocardial infarction, stroke, carotid artery stenosis, infrarenal aortic aneurysm, demetia, endogenous depression.

The three subscores were added resulting in a total CM score. A cut-off $>14$ points identified the candidates for long-term integrated care for whom standard care by the hospital social service was not considered to be sufficient, a score between 8 and 14 points indicated patients who were re-assessed 3 days post-op to achieve a final decision, and patients with a score $<8$ had no need for an individual case management.

\section{Planning}

For all $\mathrm{CM}$ patients, an individual care plan was created. It defined the care and counseling needs as well as the task of in- and out-patient professionals. Internal partners include the hospital social service. External network partners for outpatient chronic wound care include the diabetologist, the family doctor, home care providers, the pharmacy, suppliers of medical equipment, and the health insurance company.

\section{Implementation}

After the written consent of the patient and/or his relatives was obtained, the case manager generated an integrated care plan by communicating with all health care partners. Prior to discharge of the patient, prescription of drugs, medical devices and healthcare products needed for further treatment was arranged, a wound care recommendation for the primary care physician was devised 
and the patient, his relatives and the home care provider were trained in the correct use of the products.

\section{Monitoring}

Outpatient care was monitored within 48 hours of hospital discharge by telephone interview of the patient, the home care provider and the healthcare product suppliers. If necessary, the case manager saw the patient at home.

\section{Evaluation}

The first 4 weeks of outpatient care were analyzed for process dropouts or supply shortfalls. If necessary, network partners were invited to a review to optimize future outpatient care.

\section{Surgical procedures}

All 566 patients (see Tables II, III) underwent above- (AK) or below-knee (BK) bypass surgery, together with débridements of the foot or minor amputation. The bypass consisted of autologous vein, PTFE or a combination of both (composite bypass).

\section{Costs}

The costs of the clinical treatment were estimated by an algorithm for the calculation of the G-DRG revenues [15]. The costs of medical drugs were calculated individually. The DRG K01B revenue is approx. $14.000 €$. Based on these data a cost calculation per hospital case was performed using the equation

$$
\boldsymbol{h} b=r_{K 01 B}-c_{K 01 B}
$$

With $h b$ the net hospital benefit, $r_{K 01 B}$ the DRG flat rate and $c_{K 01 B}$ representing the LOS-dependent treatment costs.

\section{Statistics}

CMP, CMAO and HCG were compared using a $\chi^{2}$-test for all categorical data, t-test for continuous normally distributed, and the U-test for continuous not normally distributed variables. P-values $<0.05$ were regarded as significant. For the statistical analysis PASW Statistics 18.0 (SPSS Inc. Chicago, USA) was used.

\section{Results}

\section{Demographic data}

There were no differences between the patient groups with respect to age, sex, as well as the presence of multidrug resistant organisms requiring isolation during the hospital stay (Tables I, II). With respect to comorbidities, however, the frequency of heart failure was significantly higher in CMP than in CMAO (Table III).

\section{Surgical procedures}

Three out of 4 patients of both groups had an AK bypass, otherwise BK bypasses were performed (Table II). There was no difference with respect to the number, level or frequency of major and minor amputations between HCG and CMP as well as between CMP and CMAO (Table III). There were significantly less large débridements on the foot $(6.8 \%$ vs. $25.9 \% ; \mathrm{p}=0.04)$ and a lower need for

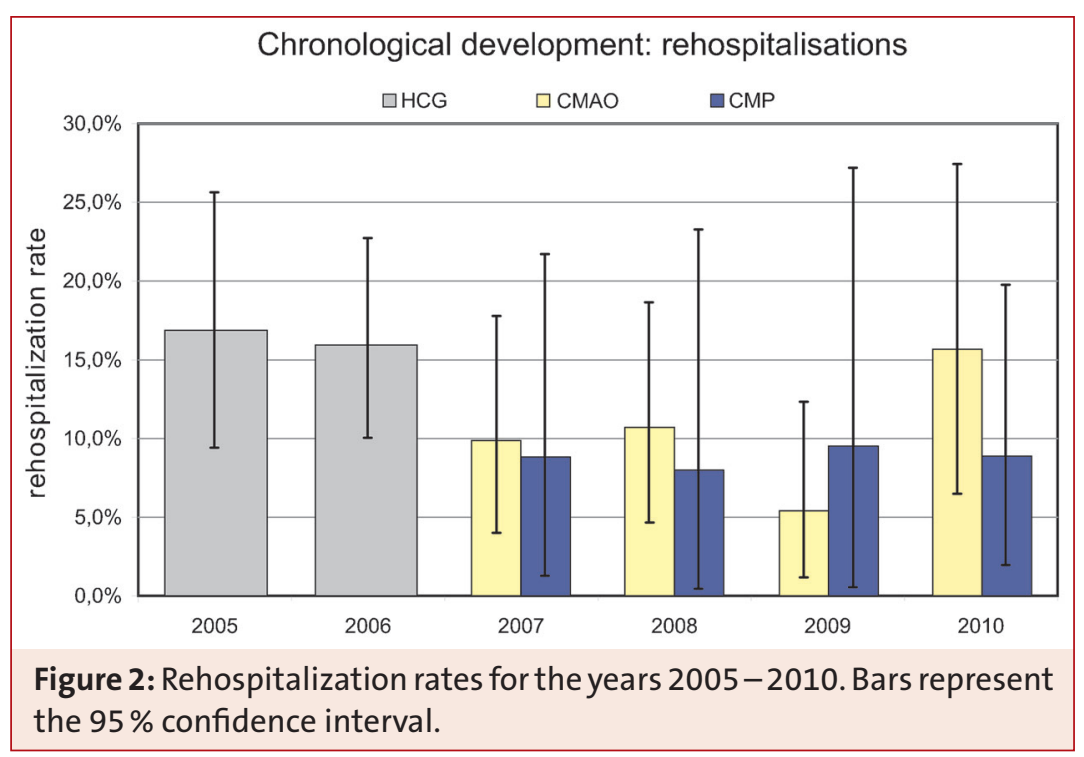

negative pressure-therapy (7.4\% vs. $22.2 \%$; $\mathrm{p}=0.003$ ) in CMAO as compared to CMP.

\section{Rehospitalization}

In HCG, 19/95 (16.4\%) patients were readmitted per year within the high trim point of the K01B DRG after the first hospital stay (total of 114 hospital admissions per year) compared with $3 / 29(8.8 \%)$ in the CMP group (total of 31 admissions per year) $(\mathrm{p}<0.001$ vs. HCG). There was no significant difference in the readmission rate between HCG and CMAO. The difference between CMAO and CMP was not significant either (Table V).

The readmission rate stayed continuously below $10 \%$ for CMP from 2007-2010 (Figure 2).

\section{Case consolidation}

The average annual case consolidation rate in HCG (Table V; Figure 3) was significantly higher than in CMP ( 17.8 vs. $9.7 \%, p<0.001$ ), while there was no such difference between CMP and CMAO.

There was a continuous drop of the case consolidation rate for CMP from 2007 to 2010 below the rates in HCG (Figure 3). 
Table V: Average rehospitalisation and case consolidation rates per year for the G-DRG K01B

\begin{tabular}{|c|c|c|c|}
\hline Average p.a. & $\begin{array}{l}\text { Historic control } \\
\text { group (HCG) })^{1}\end{array}$ & $\begin{array}{l}\text { Case management } \\
\text { patients (CMP) }{ }^{2)}\end{array}$ & $\begin{array}{l}\text { CM assessement only } \\
(\text { (CMAO) })^{2)}\end{array}$ \\
\hline K01B Patients, total & 95 & 29 & 65 \\
\hline \multicolumn{4}{|l|}{ thereof with } \\
\hline a single hospital admission & 78 & 26 & 58 \\
\hline one readmission & 16 & 3 & 7 \\
\hline two readmissions & 2 & - & 1 \\
\hline Hospital admissions, total & 114 & 31 & 73 \\
\hline Readmissions & 19 & 3 & 7 \\
\hline Readmission rate re $^{3)}$ & $16,4 \pm 0,6$ & $8,8^{*} \pm 0,6$ & $10,4^{* *} \pm 4,2$ \\
\hline Total number of cases & 95 & 29 & 65 \\
\hline Cases without a case consolidation & 78 & 26 & 58 \\
\hline Cases resulting from a case cosolidation & 17 & 3 & 7 \\
\hline Case consolidation rate ${ }^{3)}$ & $17,8 \pm 0,4$ & $9,7^{\ddagger} \pm 0,8$ & $11,2^{\ddagger \ddagger} \pm 4,3$ \\
\hline $\begin{array}{l}\text { 1) experience from } 2 \text { years } \\
\text { 2) experiennce from } 4 \text { years } \\
\text { 3) average rel. frequencies } \mathrm{p} . \mathrm{a} .[\%] \pm \mathrm{SD} \\
{ }^{*} \mathrm{p}<0,001 \text { vs. HCG } \\
{ }^{* *} \mathrm{p}=0,13 \text { vs. HCG } \\
{ }^{*} \mathrm{p}<0,001 \text { vs. HCG } \\
{ }^{\ddagger \neq} \mathrm{p}=0,12 \text { vs. HCG }\end{array}$ & & & \\
\hline
\end{tabular}

Length of hospital stay

CMAO patients had a shorter median LOS (17 - 19 days) compared to HCG from 2007 - 2010 (n.s.). The LOS for the CMP however varied over time. In 2007 and 2008 the LOS for the CMP was longer than the HCG (22 days). From 2008 to 2010 the LOS of CMP dropped significantly $(p=0.024)$ to a median of 23 days (Figure 4).

\section{Economic data}

The net benefit of a K01B case without readmission is by $2600 €$ for the hospital, whereas each rehospitalisation leading to case merge creates a deficit of approximately $1900 €$. Thus, there was a net financial benefit in the CMP group of $4500 €$ per avoided case consolidation, even before consideration of LOS. In addition, the introduction of the CM system lead to a $6.75 \%$ increase per year in reimbursable cases which equates to a surplus of approximately $16500 € /$ year per 100 admissions allocated to K01B.
In the years 2007-09 the CMP patients actually created a deficit (Figure 5), due to their excessively prolonged LOS (Figure 4). Nevertheless the gain from the additional reimbursable cases outweighed the higher treat- ment costs of the CMP leading to an overall financial benefit in the range of HCG. In 2010 there was a definite economical net benefit from the $\mathrm{CM}$. This correlates with the reduction of the LOS in the CMP subgroup (Figure 4).

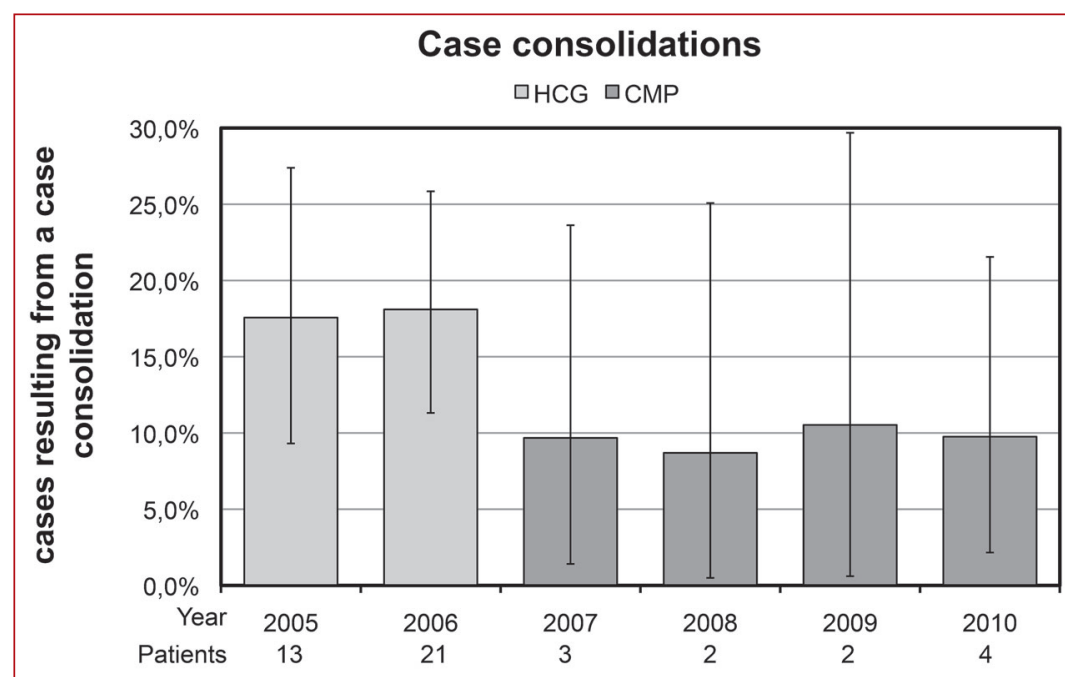

Figure 3: Case consolidation rates for HCG and CMP for the years 2005-2010. Bars represent the $95 \%$ confidence interval. 


\section{Original communication}

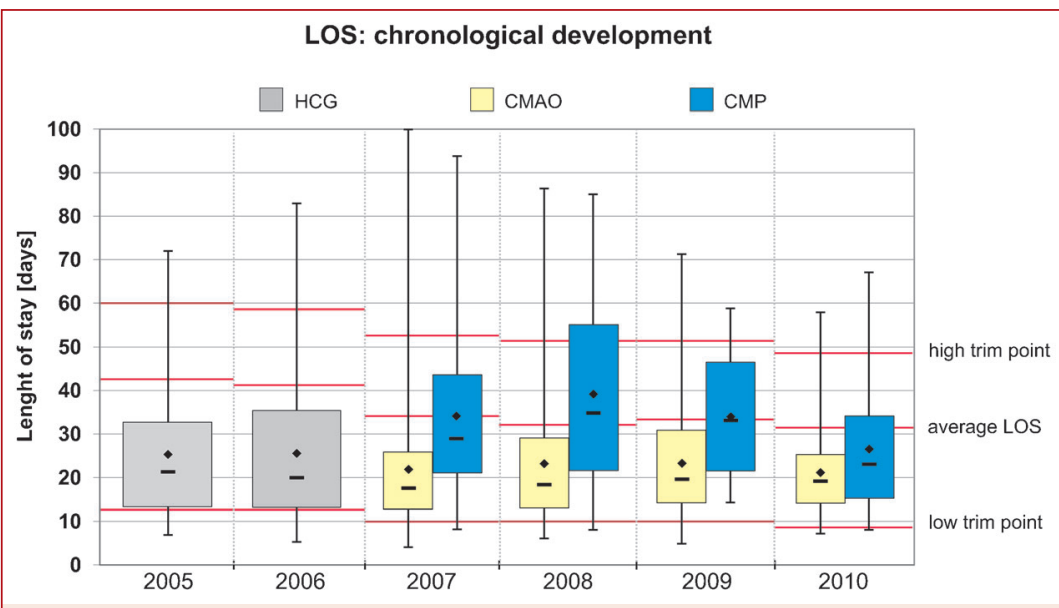

Figure 4: Boxplots of the chronological development of the hospital length of stay. The (-) represents the median length of stay, the $\left(^{*}\right)$ the mean value. The box represents the $25 \%$ to $75 \%$ percentile.

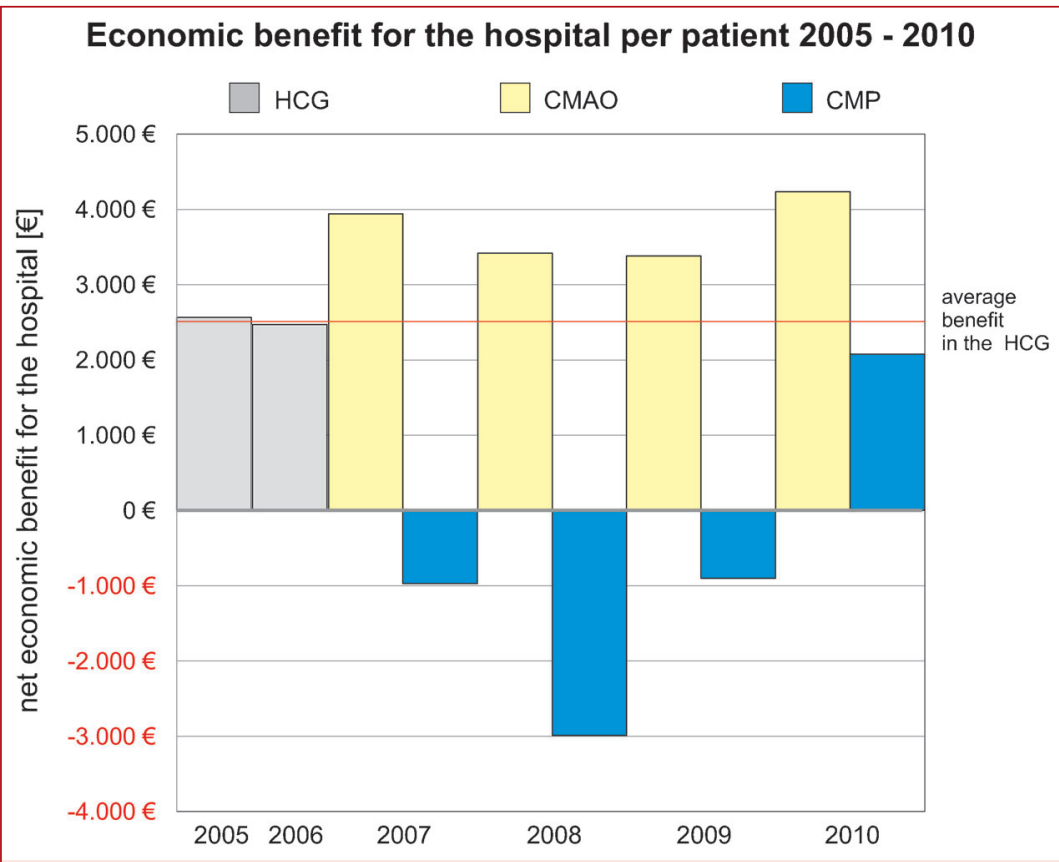

Figure 5: Chronological development of the net benefit for the hospital per case (calculation based on real G-DRG costs from 2007/2008, a DRG cost weight of 5 and a base rate of $2840 €$ ).

\section{Discussion}

Without revascularization, half of the neuroischemic DFS patients experience a major amputation, and $25 \%$ die within one year [26]. Inter- five years [24] and irrespective of amputation, patients with diabetic foot ulcers and PAD have a 5-year mortality risk twice that of diabetic foot ulcer patients without PAD at baseline [23]. Patients with diabetes, ulcers and limb loss need streamlined transition from hospital to home care, by receiving a coordinated postoperative foot service offering social, medical and surgical therapies [2]. Otherwise, the rehospitalisation rate of these patients is high [10]. The German National Guidelines on Prevention and Therapy Strategies of the diabetic foot syndrome [4] propose a system of three staged levels of patient care according to the combined UT- (3) and Wagner-classification [37] ("Wagner-Armstrong classification") (general practitioner, diabetologist specialized in diabetic foot care, specialized in-patient diabetic foot service). Despite this, the situation of DFS patients following hospital discharge after revascularization remains a problem, possibly because the above guidelines are not yet sufficiently implemented in the daily routine of outpatient care, and since inter- as well as intra-sectoral communication is poor.

Public health approaches to chronic diseases [7], such as disease-management programs [DMP] or integrated care models [12, 30, 33, 35, 36] for diabetic patients, significantly decrease hospitalization and amputation rates in Germany, confirming earlier US studies $[14,18]$. One has to keep in mind, however, that the DMP were designed primarily to organize the treatment of type 2 diabetes patients in general $[7,19,28]$. They were not focused on DFS patients, and the results cannot therefore be perfectly compared to ours. Our patients with complicated foot lesions represent only approximately $2 \%$ of the patients subscribed to DMP [28], and none of these patients is mentioned in e.g. the report of Linder et al. [19]. There are 
perfectly organized integrated care systems focused on the treatment of DFS patients in Germany (e.g. the diabetic foot network Cologne; $12,30)$, but they are not yet implemented nationwide. Also the patients described in these reports are not fully comparable to ours, since only a minor portion of them had extensive foot lesions and needed hospital treatment, e.g. for arterial revascularization. Data on the rehospitalisation rates of DFS patients are lacking. There are also critical reports on the effects of the DMP [19].

In contrast to DMP and integrated care, case management (CM) models are focused on optimized individual outcome [5]. Our integrated CM system of outpatient care according to hospital quality standards significantly lowers rehospitalization and case consolidation rates of ischemic DFS patients with infrapopliteal bypasses and complicated foot wounds without worsening the economic situation of the hospital. As far as we are aware, a similar CM model eliminating the barriers between the hospital and outpatient sectors has not been described in Germany.

In-hospital CM systems normally serve as LOS management tools for admission and discharge, navigating the patient through the clinical procedures without time loss, and organizing clinical follow-up. But this is not an integrated trans-sectoral approach with out-patient care. A diabetes expert team making joint visits with primary care teams together with their patients and relatives was described to improve the standards of care for diabetic patients [21]. However, this approach was not truly integrated. One hospital-based CM was reported to improve diabetes care, patient outcome, partnership between hospital medical team workers and community health resources, as well as the implementation of guidelines [6]. Another integrated hospital ap- proach focusing on foot care for DFS patients improved primary care staffs' knowledge and patients' attitudes, and the number of appropriate referrals to acute specialist services was increased [8]. The integration of a "Diabetic Foot Practioneer" into a clinical diabetic foot care team [9] who managed a fast-track vascular program for ischemic patients reduced the mean LOS from 59 to 34 days. Of note however, the LOS was much longer than in our study.

Our integrated CM system bridging in- and out-patient care improves the hospital's economic situation which is threatened by old patients with chronic diseases. The estimated number of people with diabetes in Germany is eight millions [29]. DFS accounts for approximately $50 \%$ of the costs associated with hospitalization patients with diabetes (38). Our $\mathrm{CM}$ system increases the number of reimbursable hospital cases due to a reduction of case consolidation and rehospitalisation. It might be concluded that our CM works solely by increasing LOS, however, the LOS of CMP decreased from year to year (Figure 4) without affecting the rehospitalization rate (Figure 2) indicating that the beneficial effect of the CM system is independent of LOS. The drop in LOS may indicate a learning curve of the CM organization. In the beginning the patients were treated with exceptional care and attention and were kept relatively long in the hospital. After these processes had become routine, the LOS became shorter. However the LOS of CMP still remains longer than for patients without $\mathrm{CM}$ intervention. This can be explained by selection of the most problematic patients with the worst social situation and the most urgent need for intensive post-acute care by the CM, as well as the additional time needed to organize the outpatient network. These differences in the clinical complexity are neither reflected by the K01B flat rate, nor by standard scores for the improvement of discharge management (BRASS, Barthel; 22, 20). Our tripartite scoring system comprising medical, nursing and social criteria possibly overcomes this problem. However as yet our score has not been evaluated systematically.

Since there were no comparable data published when we started our CM project in 2007, a retrospective study design was inevitable. The direct comparison of the effects of the $\mathrm{CM}$ on patients with comparable risk scores is still lacking. In order to better discriminate a positive effect of the CM, we compared a subgroup of high risk patients (CMP) with overall lower risk patient groups (HCG, CMAO). This bias certainly lowers the scientific value of our data. The direct comparison would have required an RCT protocol, which, at that time, would have lacked any scientific background owing to the fact that there were no comparable CM programs described in the literature. On the other hand, the significant decrease of the rehospitalisation rate of CMP versus the HCG has to be interpreted as highly successful. Although the medical risk score of the CMP and the CMAO group was not significantly different our CM filtered out the most problematic patients with critical comorbidities (e.g. heart failure), the worst social situation (e.g. living alone without relatives) as well as the highest need for intensive post-acute care. The comparison with lower-risk groups (HCG, CMAO) underestimates the potentials of CM intervention. Given the CMAO group accounting for $69 \%$ of the patients assessed by the CM had an intrinsic rehospitalisation rate of $10.4 \%$, a model calculation would show that the rehospitalization rate in the CMP subgroup would approach $30 \%$ in the absence of CM intervention. Such a percentage appears more realistic than the $16.8 \%$ in the HCG 
which was heterogenous too with respect to medical, social and post-acute care criteria.

Patient selection may also explain why the readmission and case consolidation rate of the CMP patients was not different from those patients who did not receive full attention of the $\mathrm{CM}$ following the assessment (CMAO).

Now that we know the potentials of our CM, prospective studies may follow, hopefully giving results of better validity and scientific evidence.

The patients, their relatives as well as the primary care physicians highly appreciate the activities of the CM. Avoidance of readmissions into the hospital contributed to a better wellbeing of the patients concerned.

\section{Conclusions}

Our integrated CM system has become a marketing tool and is therefore a good investment in the future.

\section{Acknowlegements}

We would like to express our deep gratitude to Dr. Frances Game, Derby, U.K. for her critical revision of our manuscript.

We thank Dr. Johannes-Georg Böttrich for technical help and the general support of the study.

The installation and evaluation of the case management organization was partly supported by a sales-independent project management and scientific expert team of the B. Braun Melsungen AG, Germany.

\section{Conflicts of interest}

There are no conflicts of interest existing.

\section{References}

1 Albers M, Romiti M, Brochado-Neto FC, De Luccia N, Pereira CA. Meta-analysis of popliteal-to-distal vein bypass grafts for critical ischemia. J Vasc Surg 2006; 43: 498 - 503

2 Armstrong DG, Bhara M, White M et al. The impact and outcomes of establishing an integrated interdisciplinary surgical team to care for the diabetic foot. Diab Metab Res Rev 2012 ("Accepted Article"; doi: 10.1002/dmrr.2299)

3 Armstrong DG, Lavery LA, Harkless LB. Validation of a diabetic wound classification system. The contribution of depth, infection, and ischemia to risk of amputation. Diabetes Care 1998; 21: 855-9

4 Bauer H, et al. Nationale VersorgungsLeitlinie Typ II-Diabetes - Präventions- und Behandlungsstrategien für Fußkomplikationen. Mainz, Kirchheim, 2009 (www. diabetes.versorgungsleitlinie.de)

5 Case Management Society of America. "Definition of Case Management”. http://www.cmsa.org/ Default.aspx?tabid=104. Retrieved 30.8.2010

6 Chang HC, Chang YC, Lee SM, Chen MF, Huang MC, Peng CL, Yan CY. The effectiveness of hospital-based diabetes case management: an example from a northern Taiwan regional hospital. J Nursing Rs 2007; 15: 296-308

7 DMAA: Wellness, Disease and Care Management: Background for Developing a Business Strategy. http://www.carecontinuumalliance. org/pdf/DMAA-NAM_Employer_ Toolkit.pdf

8 Donohue ME, Fletton JA, Hook A, Powell R, Robinson I, Stead JW, Sweeney K, Taylor R, Tooke JE. Improving foot care for people with diabetes mellitus - a randomized controlled trial of an integrated care approach. Diab Med 2000; 17: $581-587$
9 Doxford MJ, Rashid H, Edmonds M.E. The Diabetic Foot Practioneer - a new approach to diabetic foot in-patient care, resulting in a reduction of hospital length of stay. 4th International Meeting on the Diabetic Foot, Noordwijkerhout, The Netherlands, 2003, O 22

10 Goshima KR, Mills JL Sr., Hughes JD. A new look at outcomes after infrainguinal bypass surgery: traditional reporting standards systematically underestimate the expenditure of effort required to attain limb salvage. J Vasc Surg 2004; 39: 330 - 335

11 Heller G, Günster C, Swart E. Über die Häufigkeit von Amputationen unterer Extremitäten in Deutschland. Dtsch Med Wochenschr 2005; 130: 1698 - 1690

12 Hochlenert D, Engels G, Altenhofen L. Integrierte Versorgung: Ergebnisse des Netzwerkes Diabetischer Fuß Köln und Umgebung. Deutsches Ärzteblatt 2006; 103 (24): A1680A1683

13 Holstein P, Ellitsgaard N, Olsen BB, Ellitsgaard V. Decreasing incidence of major amputations in people with diabetes. Diabetologia 2000; 43: 844-847

14 Horswell RL, Birke JA, Patout CA Jr. A staged management diabetes foot program versus standard care: a 1-year cost and utilization comparison in a state public hospital system. Arch Phys Med Rehabil. 2003; 84 (12): 1743 - 1746

15 Institut für das Entgeltsystem im Krankenhaus (InEK). Handbuch zur Kalkulation von Fallkosten. Version 3.0 - 10.Juli 2010 (www.g-drg.de)

16 International Working Group on the Diabetic Foot. International Consensus on the Diabetic Foot \& Practical Guidelines on the Diabetic Foot 2011. www.idf.org/bookshop

17 Joyce PR, Khan A, Jones AV. The revolving door patient. Comprehensive Psychiatry 1981; 22: 397 - 403

18 Lavery LA, Wunderlich RP, Tredwell JL. Disease management for the dia- 
betic foot: effectiveness of a diabetic foot prevention program to reduce amputations and hospitalizations. Diabetes Res Clin Pract 2005; 70: $31-37$

19 Linder R, Ahrens S, Köppel D, Heilmann T, Verheyen F. The benefit and efficiency of the disease management program for type 2 diabetes. Dtsch Arztebl Int 2011; 108 (10): 155 - 162. DOI: $10.3238 /$ arztebl.2011.0155

20 Mahoney F, Barthel D. Functional evaluation: The Barthel Index. Maryland State Med J 1965; 14: 56-61

21 McCullough DK, Price MJ, Hindmarsh $\mathrm{M}$, Wagner EH. A population-based approach to diabetes management in a primary care setting: early results and lessons learned. Eff Clin Pract 1998; 1: $12-22$

22 Mistiaen P, Duijnhouwer RN, Prins-Hoekstra A, Ros W, Blaylock A. Predicitve validity of the BRASS index in screening patients with post-discharge problems. J Adv Nurs 1999; 30: 1050 - 1056

23 Morbach S, Furchert H, Gröblinghoff U, Hoffmeier H, Kersten K, Klauke G.T, Klemp U, Rümenapf G, Haastert B, Bharara M, Armstrong DG. Long-Term Prognosis of Diabetic Foot Patients and their Limbs: Amputation and Death over a Decade. Diabetes Care 2012; 35: 1-7

24 Morbach S, Müller E, Reike H, Risse A, Rümenapf G, Spraul M. Evidenzbasierte Leitlinien. Diagnostik, Therapie, Verlaufskontrolle und Prävention des diabetischen Fußsyndroms. Diabetologie 2009; 4: $301-325$

25 Myosidis T, Nowack T, Eickmeyer F, Waldhausen P, Brunken A, Hochlen- ert D, Engels G, Santosa F, Luther B, Kröger $\mathrm{K}$. Trends in amputations in people with hospital admissions for peripheral arterial disease in Germany. Vasa 2011; 40: 289-295

26 Norgren L, Hiatt WR, Dormandy JA, Nehler MR, Harris KA, Fowkes FGR. Inter-Society Consensus for the Management of Peripheral Arterial Disease (TASC II). Eur J Vasc Endovasc Surg 2007; 33:S1 - 75

27 Papanas N, Maltezos E, Edmonds M. Salvation of the diabetic foot: Still a quest for the holy grail? Vasa 2011; 40: 267 - 269

28 Qualitätssicherungsbericht: Disease-Management-Programme in Nordrhein. www.kvno.de/downloads/qualbe dmp10.pdf

29 Rathmann W, Haastert B, Icks A, Lowel H, Meisinger C, Holle R, Giani G. High prevalence of undiagnosed diabetes mellitus in Southern Germany: target populations for efficient screening. The KORA survey 2000. Diabetologia 2003; 46: 182 - 189

30 Risse A, Hochlenert D. Integrierte Versorgung. Neue (?) Versorgungsform am Beispiel des diabetischen Fußsyndroms. Diabetologe 2010 DOI 10.1007/s11428-009-0480-3

31 Sauvant G, Hüttenmoser B, Soyka P, Rüttimann S. New possibilities of maximal revascularization of the foot as a limb salvage procedure in diabetics. Vasa 2010; 39: 278-283

32 Simms M. Surgical treatment of the diabetic foot. J Cardiovasc Surg 2009; 50: 293 - 311

33 Stein V, Rieder A. Lost in transition - meeting the challenge through integrated care. Highlights from the $9^{\text {th }}$ International Conference on Integrated Care in Vienna. Int J Integr Care 2009; 9: 1 - 11
34 Sumpio BE, Armstrong DG, Lavery LA, Andros G, The role of interdisciplinary team approach in the management of the diabetic foot. A joint statement from the Society for Vascular Surgery and the American Podiatric Medical Asssociation. J Vasc Surg 2010; 51: $1504-1506$

35 Trautner C, Haastert B, Mauckner P, Gätcke LM, Giani G. Reduced incidence of lower-limb amputations in the diabetic population of a German city, 1990 -2005: results of the Leverkusen Amputation Reduction Study (LARS). Diabetes Care, 2007; 30: $2633-2637$.

36 Ullrich W, Marschall U, Graf C. Versorgungsmerkmale des Diabetes mellitus in Disease-ManagementProgrammen. Diabetes, Stoffwechsel und Herz 2007; 6: 407 - 414

37 Wagner FW Jr. The dysvascular foot: a system for diagnosis and treatment. Foot Ankle 1981; 2: 64- 122

38 Williams DR. Hospital admissions of diabetic patients: information from hospital activity analysis. Diab Med 1985; 2: 27-32

\section{Correspondence address}

Gerhard Rümenapf, MD, $\mathrm{PhD}$ Department of Vascular Surgery Diakonissen-Stiftungs-Krankenhaus Speyer Hilgardstr. 26

DE-67346 Speyer

Germany

gerhard.ruemenapf@diakonissen.de

Submitted: 21.06 .2012

Accepted after revision: 17.08.2012 